УДК $78.03+782.8$

Светлана Петровна Поляковская, кандидат искусствоведения, преподаватель-методист Винницкого училища культуры и искусств имени М. Д. Леонтовича poliakovska@gmail.com

\title{
ЭЛЕМЕНТЫ ГРОТЕСКА В МУЗЫКАЛЬНОМ ЯЗЫКЕ МЮЗИКЛА «ОДНАЖДЫ В ОДЕССЕ... ИЛИ СОНЬКА ЗОЛОТАЯ РУЧКА» СИЯНЫ ЛОСИНСКОЙ
}

Цель исследования - выявить проявления гротеска в музыкальном языке мюзикла «Однажды в Одессе... или Сонька Золотая Ручка» Сияны Лосинской. Методология исследования опирается на сформированную М. М. Бахтиным в рамках литературоведения теорию гротеска, изложенную в работе «Творчество Франсуа Рабле и народная культура средневековья и Ренессанса». Научная новизна исследования. Данное исследование открывает направление определения специфики воплощения гротескной образной сферы в жанре мюзикла, для которого гротеск как художественный приём является имманентно свойственным. Впервые предпринимается попытка исследования специфики музыкального гротеска на материале музыки современного одесского композитора С. Лосинской. Выводы. Для воплощения гротескной образной сферы в мюзикле использованы такие музыкально-стилистические приёмы, как стилизация, цитирование, соединение разножанровых элементов. Это и определяет специфику музыкального материала мюзикла, цементирующим элементом для которого становится «словарь одесских музыкальных интонаций». Тонкая стилизация музыкального материала создаёт у слушателя иллюзию узнавания.

Ключевые слова: музыкальная комедия, гротескная образная сфера, стилистика музыкального языка.

Polyakovskaya Svetlana. Ph.D. in the History of Art, professor of Vinnytsia Music College of Culture and Arts named after M. Leontovych

Elements of grotesque in the musical language of the musical «Once in Odessa... Or Sonya - Golden Hand» by Siyana Losinskaya

Article purpose - to reveal manifestations of grotesque in musical language of the musical «In Odessa once ... Or Sonka - the Gold Handle» of Siyana Losinskaya. The methodology of a research is guided by the theory of grotesque created by M. M. Bakhtin within literary criticism stated in work «Francois Rabelais's creativity and the national culture of the Middle Ages and the Renaissance». Scientific novelty of a research. This research opens the direction of determination of specifics of the embodiment of the grotesque figurative sphere

(C) Поляковская С. П., 2016 
in a genre of the musical for which the grotesque as artistic touch is immanently peculiar. An attempt of a research of specifics of musical grotesque on material of music of the modern Odessa composer S. Losinskaya is for the first time made. Conclusions. For the embodiment of the grotesque figurative sphere, in the musical such musical and stylistic receptions as stylization, citing, connection of different genres elements are used. It also defines specifics of musical material of the musical for which «the dictionary of the Odessa musical intonations» becomes the cementing element. Thin stylization of musical material creates recognition illusion at the listener.

Keywords: musical comedy, grotesque figurative sphere, stylistics of musical language.

Поляковська Світлана Петрівна, кандидат мистецтвознавства, викладач-методист Вінницького училища культури і мистецтв імені М. Д. Леонтовича

Елементи гротеску у музичній мові мюзиклу «Одного разу в Одесі... або Сонька Золота Ручка» Сіяни Лосинської

Мета дослідження - виявити прояви гротеску в музичній мові мюзиклу «Одного разу в Одесі... або Сонька Золота Ручка» Сіяни Лосинської. Методологія дослідження спирається на сформовану М. М. Бахтіним в рамках літературознавства теорію гротеску, викладену в роботі «Творчість Франсуа Рабле і народна культура середньовіччя і Ренесансу». $\mathbf{H a -}$ укова новизна дослідження. Дане дослідження відкриває напрям визначення специфіки втілення гротескної образної сфери в жанрі мюзиклу, для якого гротеск як художній прийом є іманентно властивим. Вперше робиться спроба дослідження специфіки музичного гротеску на матеріалі музики сучасного одеського композитора С. Лосинської. Висновки. Для втілення гротескної образної сфери в мюзиклі використані такі музично-стилістичні прийоми, як стилізація, цитування, з'єднання різножанрових елементів. Це і визначає специфіку музичного матеріалу мюзиклу, цементуючим елементом для якого стає «словник одеських музичних інтонацій». Тонка стилізація музичного матеріалу створює у слухача ілюзію впізнавання.

Ключові слова: музична комедія, гротескна образна сфера, стилістика музичної мови.

Актуальность темы исследования обуславливается тем, что при очевидной значимости понятия гротеска в современной музыкальной культуре стройная теория музыкального гротеска в рамках музыковедческого знания на сегодняшний день все еще не сформирована. Отдельно важным направлением исследования данного понятия является его проявление в музыкально-сценических комедийных жанрах, где гротескная образная сфера реализует себя на разных ком- 
позиционных уровнях, от концептуально-содержательного до стилистически-языкового. С этой точки зрения, безусловно, продуктивным представляется изучение гротескных художественных приемов в жанре мюзикла как одного из жанровых подвидов музыкальной комедии.

Научная новизна исследования. Данное исследование открывает направление определения специфики воплощения гротескной образной сферы в жанре мюзикла, для которого гротеск как художественный приём является имманентно свойственным. Впервые предпринимается попытка исследования специфики музыкального гротеска на материале музыки современного одесского композитора С. Лосинской. Определение конкретных музыкально-стилистических приёмов, при помощи которых воплощается гротескная образная сфера, может послужить вкладом в создание теории музыкального гротеска.

Цель исследования - выявить проявления гротеска в музыкальном языке мюзикла «Однажды в Одессе... или Сонька Золотая Ручка» Сияны Лосинской. Достижение этой цели предполагает решение следующих задач:

1) обозначить, на каких композиционных уровнях проявляет себя гротескная образная сфера в данном произведении;

2) определить стилистические приемы реализации гротескных образов в музыкальном языке мюзикла.

Методология исследования опирается на сформированную М. М. Бахтиным в рамках литературоведения теорию гротеска, изложенную в работе «Творчество Франсуа Рабле и народная культура средневековья и Ренессанса». Проекция сформированных на общеэстетическом уровне сущностных черт гротеска непосредственно в интонационно-языковую сферу может послужить созданию музыковедческой теории данного понятия.

Изложение основного материала. Жанр мюзикла, как разновидность музыкальной комедии, на сегодняшний день является одним из наиболее популярных театральных жаров. Широта сюжетно-содержательного спектра, зрелищность, универсализм музыкального языка, ориентированного, прежде всего, на современный интонационный словарь, обеспечивает ему признание у достаточно широких слоев публики. Именно мюзиклы составляют значительную часть в репертуарах отечественных и зарубежных театров музыкальных комедий. Не является исключением и Одесский театр имени М. Водя- 
ного, который за свою более чем 50-летнюю историю существования превратился в один из символов города. Ведь сам жанр музыкальной комедии оказался близок одесскому характеру, подразумевающему своеобразное чувство юмора и поликультурные взаимодействия, создающие неповторимый одесский колорит. Представляется интересным, что среди спектаклей, составляющих репертуар Одесского тетра музыкальной комедии, в отдельный ряд выстраиваются произведения с одесской тематикой, написанные на сюжеты из истории города одесскими сценаристами и композиторами. К примеру, мюзиклы «Граф Воронцов» (либретто и музыка Евгения Ульяновского) и «Хаджибей, или Любовь к трём тысячам апельсинов» на музыку из любимых зрителями мюзиклов и оперетт (либретто Игоря Лосинского и Яна Гельмана). Этот ряд продолжает джаз-мюзикл «Однажды в Одессе... Или Сонька Золотая Ручка», прозвучавший в апреле 2016 года в стенах театра музкомедии во время празднования Международного дня джаза. Либретто по пьесе Яна Гельмана было написано Игорем Лосинским, в качестве композитора дебютировала выпускница одесской консерватории, автор ряда музыкальных произведений Сияна Лосинская.

Изящный авантюрный сюжет из жизни легенды бандитской Одессы Софьи Блувштейн воплощён на основе типично одесского музыкального материала с соблюдением всех законов жанра мюзикла. Именно «одесскость» музыкального языка, так же как и своеобразие литературного стиля сценария, обеспечивает органичность воплощения темы. Примечательна фраза, которой в либретто заканчивается перечень действующих лиц: «Общая любовь у всех персонажей одна: Одесса - город, где они торгуют, воруют, ловят, лечат, любят и ненавидят». Эта же любовь к родному городу у моря объединила и авторский состав. Идея создания мюзикла принадлежала Яну Альбертовичу Гельману - известному одесскому сценаристу, троекратному чемпиону игр КВН, художественному руководителю команды КВН «Джентльмены ОГУ», автору ряда передач и телепроектов («Городок», «Утренняя почта», «Голубой огонёк»), обладателю премии Тэффи. Работая в области юмористических проектов, как в Одессе, так и в Москве, Ян Гельман всегда был предан родному городу, что отражалось в его литературном стиле, презентующем собой высокий образец одесского остроумия. Сценарист руководствовался идеей постановки спектаклей на основе пьес, написанных им «для Одессы» и «про Одессу» (первым был спектакль-ревю «Карнавал на Французском 
бульваре», который с успехом шёл в 90-е годы). Как и «Хаджибей, или Любовь к трём тысячам апельсинов», пьеса «Однажды в Одессе... или Сонька Золотая Ручка» создана на основе нескольких исторических анекдотов из жизни города, с участием реальных персонажей, представленных, впрочем, в несколько необычном свете. Большой поклонник Одесского театра музыкальной комедии, автор надеялся увидеть на его сцене историю Соньки в жанре мюзикла. Музыку он предложил написать Сияне Лосинской, для которой это произведение стало первой крупной работой в музыкально-театральном жанре. По словам композитора, «мюзикл писался легко, т. к. образы были очерчены очень выпукло и ярко, текст сценария органично ложился на музыку, слова вокальных номеров «пелись», одесская музыкальная лексика угадывалась в оборотах речи». И хотя произведение вскоре было готово, работы по подготовке постановки прекратились в связи с трагической смертью Яна Гельмана в 2012 году.

Новая возможность дать мюзиклу сценическую жизнь появилась в 2016 году, когда в рамках «Джазовых дней в Одессе» «Соньку Золотую Ручку» взялся исполнить Джазовый театр Михаила Фрейдлина. Ограничения по времени, связанные с фестивальным форматом, потребовали более чем значительного сокращения сценария. Кроме того, необходимо было работать в стилистических рамках, установленных совсем недавно родившимся джазовым театром, который искал и находил новые, нестандартные подходы к театральному искусству. Необходимые изменения и дополнения были выполнены «соавтором по перу» Яна Гельмана, другом и товарищем по КВНу, сценаристом Игорем Лосинским. Несмотря на то, что в результате сокращений были выведены из действия несколько сюжетных линий, представленных весьма колоритными персонажами (влюблённая пара Нюся и Мося, два жандарма, купцы первой гильдии), джаз-мюзикл получился очень цельным и динамичным в драматургическом плане. А главное - очень «одесским», что и соответствовало первоначальной идее. И так как неотъемлемая черта одесского мышления - это ирония, и в частности самоирония, персонажи спектакля представлены в несколько гротескном свете.

Гротеск как художественный приём имманентно свойствен жанру музыкальной комедии. Типичные для оперетт и мюзиклов сюжетные коллизии, основанные на подменах, обмане ожиданий, переодеваниях, разоблачениях и перевоплощениях, предполагают переведение 
действия из одного плана в другой, а на языковом уровне - смешение разнородных элементов. В комедийных жанрах часто происходит «возвышение банального» и «банализация возвышенного», что свидетельствует об их связи с карнавальным типом мышления. Именно амбивалентность, наряду со склонностью к противоречивости и несоответствием требованиям эстетики прекрасного и возвышенного, М. М. Бахтин выделяет как сущностные черты гротеска в своем исследовании «Творчество Франсуа Рабле и народная культура Средневековья и Ренессанса» [1].

Причудливое соединение правды и вымысла, прекрасного и безобразного, трагического и комического, достоверного и маловероятного создает особую поэтику музыкально-комедийных жанров. А преувеличения отдельных черт сценических персонажей представляют их в несколько (или в полностью) карикатурном виде, что и вызывает у зрителей смеховую реакцию. Хотя гротеск порой и будит «горький смех», «смех сквозь слёзы», поскольку часто апеллирует к болевым аспектам бытия, юмор музыкально-комедийных жанров, как правило, добрый и вызывает светлый, позитивный, радостный смех.

В этом смысле не является исключением и мюзикл «Однажды в Одессе... или Сонька Золотая Ручка». Гротескный подход реализован уже в самой подаче центральных образов. В соответствии со сценарием, Софья Блувштейн характеризуется следующим образом: «она же - графиня Сан Донато, баронесса Бобруйско-Желобинская, княгиня Буйнакская, она же - Сонька Золотая Ручка - королева воров. Любит риск, азарт и Михеля Блувштейна». Образ главной героини в пьесе крайне идеализирован и романтизирован. Сонька представлена в виде светской дамы, утончённой и изысканной, с безупречными манерами и тонким вкусом, что очевидно соответствует только одной из масок, которую носила эта разносторонняя преступница-авантюристка. Кроме того, в мюзикле она - воплощение женской верности, тогда как у настоящей Соньки, по самым скромным подсчетам, было пятеро официальных мужей, не считая прочих соблазнённых и одураченных представителей мужского пола. Эта нарочитая возвышенность образа в сочетании с противозаконными деяниями отражена и в музыкальной характеристике главной героини. Презентацией образа является романс Соньки «Где любви моей начало?», преисполненный глубокого и искреннего лиризма. Однако уже в следующем вокальном номере в партии Соньки композитор использует гротеск- 
ный приём. В тематизм страстного танго «Я буду ждать» в припеве вторгается мотив канкана. Цитирование танца, долго считавшегося непристойным, но нашедшим свое место в оперетте, удачно подчеркивает смысл текста:

Я буду ждать его, любви не рвётся нитка.

Пусть знает он, я очень верно буду ждать.

Я буду ждать, как ждать умеют одесситки,

Но только так, чтоб даром, даром время не терять!

Ещё один номер в исполнении Соньки - «Ювелирная кадриль» снова характеризует её как страстно любящую натуру. Однако на сей раз объект её любви - это драгоценности, и тут усомниться в искренности чувств героини невозможно. Средства музыкальной выразительности в этом номере просты и убедительны. Композитор использует типичные для опереточных кадрилей XIX века гармонические обороты и фактурные решения. Мелодия строится на сочетании широких ходов и гаммаобразного движения. Скользящие полутоновые интонации подчеркивают внутренний трепет, который испытывает Золотая Ручка по отношению к бриллиантам:

Мы без драгоценностей, ну, просто в неглиже!

Чтобы все мы делали без Карла Фаберже!

Данная двойственность обрисовки главного действующего лица служит не только углублению образа, но также позволяет шире использовать музыкальный материал, а также «раскачивать» зрителя отсутствием одноплановости, когда герой представлен либо «злодеем», либо «героем». И действительно, в поступках Соньки мало героического, но зритель не устает восхищаться иронией, мастерством и лёгкостью, с которой она осуществляет свои достаточно опасные трюки. Музыкальные переходы от лирики к сарказму и обратно усиливают степень эмоционального воздействия.

Образ Михеля Блувштейна в мюзикле также представлен в романтическом свете: «На первый взгляд он похож на обыкновенного вора - он хорошо одет, у него прекрасные манеры и если он и отличается чем-то от приличной публики, то только в лучшую сторону. Необычное в нём то, что он вор-романтик. Чаще всего работает в одиночку, предпочитая преступления не столько выгодные, сколько красивые по исполнению». Тем не менее Михель символизирует мир бандитской Одессы, мир, организованный по своим внутренним правилам, со своим кодексом чести: 
Одесские жиганы друг в друга не стреляют, Одесские жиганы друг другу - братаны!

Одесские красотки, когда с другим гуляют, То своему навеки в душе всегда верны!'

В музыкальном отношении этот номер («Бандитская кадриль») является средоточием интонационных «вульгаризмов». Композитор весьма естественно использует стилистику одесского блатного шансона: в припеве, как говорится, «веет цыганщиной». Без прямого цитирования воспроизводится музыкально-языковая среда, аутентичная для изображаемых персонажей.

Лирическая сторона образа Михеля раскрывается в его дуэтах с Сонькой. Примечательно, что его вокальная партия полностью строится на интонациях романса Золотой Ручки. Это дуэт согласия, в котором эмоционально-интонационный импульс задаёт героиня, а Михель лишь вторит ей, но вторит искренне. В сценическом воплощении этого дуэта режиссер-постановщик использовал популярный в мюзиклах приём удвоения образов. Пару исполнителей главных ролей дублирует пара танцоров. Таким образом, внутренние переживания персонажей воплощаются на сцене как вокально-интонационными, так и хореографическими средствами.

Ешё два персонажа, которых в этой истории можно отнести к главным, - это Иван Перфильевич Тазиков («негоциант, любит скобяные и ювелирные изделия, ими же и торгует») и Карл Готлиб Лубенау фон Вайнер («профессор психиатрии, любит тяжёлые психические отклонения»). Оба обрисованы в карикатурно-гротескном свете. Исполнителями этих ролей стали молодые, но уже опытные артисты Театра музыкальной комедии. Им было не впервой представлять на сцене персонажей, которые, с помощью актёрских преувеличений, должны вызывать смех у публики. Умение не только грамотно петь, но однозначно точно расставлять акценты в тексте песен способствовало воплощению авторского замысла.

Иван Тазиков - типичный комедийный персонаж, жаждущий одурачить клиента и, в результате, ловко одураченный Золотой Ручкой. Он лишён собственной музыкальной характеристики, однако подхватывает мотив «Ювелирной кадрили», ведь любовь к драгоценностям - его основная страсть.

Доктор психиатрии, напротив, персонаж с ярко индивидуализированной характеристикой. Именно с его участием происходят сцены, связанные с комедийной развязкой этой авантюрной истории. 
Гротескный образ лекаря немецкого происхождения создаётся, прежде всего, при помощи своеобразного литературного языка, построенного на смешении русских и немецких слов.

Майне либер идиоты!

Их либе зих!

Без дебилов нет работы!!

И денег нихт!

Но пока бракоцефалов

Есть в империи немало!

Кто ж не псих в державе нашей?

Кто же не псих?

«Куплеты психиатра» строятся на нарочито простых и чётко ритмически организованных мотивах, что, вероятно, должно отражать специфику популярных немецких народных песен и военных маршей. Ещё одна музыкальная деталь, указывающая на национальность доктора, - это цитирование австрийской народной песни «Ах, мой милый Августин» о горе-певце, выжившем во время чумы благодаря пристрастию к алкоголю. Впрочем, эта цитата не прописана в партитуре, а возникла в постановочной версии.

Что касается джазового элемента, то он не столько свойствен авторскому музыкальному материалу, сколько привнесён в ярких аранжировках, выполненных композитором Олегом Негруцей и музыкантом Владимиром Вакуловичем. Инструментальный состав, задействованный в постановке, соответствует джазовому ансамблю (кларнеты, тенор саксофоны, трубы, тромбоны, банджо, фортепиано, ударные, контрабас).

Свой вклад в то, чтобы музыкальная составляющая соответствовала юмористическому характеру мюзикла, внёс руководитель джазансамбля Игорь Знатоков. В этом ему, безусловно, помог тот опыт, который он, успешно солирующий саксофонист, приобрёл во время работы в качестве дирижёра оркестра Одесского цирка, где гротеск является неотъемлемой частью действия.

Выводы. Таким образом, для воплощения гротескной образной сферы в мюзикле использованы такие музыкально-стилистические приёмы, как стилизация, цитирование, соединение разножанровых элементов. Это и определяет специфику музыкального материала мюзикла, цементирующим элементом для которого становится, назовём его так, «словарь одесских музыкальных интонаций». Тонкая стилизация музыкального материала создаёт у слушателя иллюзию 
узнавания, когда мелодии уже при первом прослушивании кажутся знакомыми и прекрасно запоминаются.

В произведении не предусматривалась лейтмотивная система, однако музыкально-драматургическая целостность образуется соединением трёх основных тем - лирической, гротескно-комедийной и «темы любви к Одессе», которая особенно ярко воплощена в первом и заключительном музыкальных номерах.

Даже сокращенная версия позволяет судить о несомненных достоинствах произведения: изящный ироничный стиль литературного сценария, динамичность драматургического развития, яркость воплощения характеров главных персонажей, органичность музыкального языка, презентующего колоритный «одесский сленг». Всё это даёт основания предположить, что мюзикл «Однажды в Одессе... или Сонька Золотая Ручка» займёт достойное место в ряду комедийнотеатральных произведений одесских композиторов.

\section{СПИСОК ЛИТЕРАТУРЫ}

1. Бахтин М. Творчество Франсуа Рабле и народная культура средневековья и Ренессанса. М.: Художественная литература, 1990. 543 с.

2. Ковальская И. Сюжетно-тематические основы и жанровые свойства музыкальной комедии (на примере репертуара Одесского академического театра музыкальной комедии имени М. Водяного): дис. ... канд. юрид. наук: 12.00.06 / Одесса, 2016. 167 с.

\section{REFERENCES:}

1. Bakhtin, M (1990). Works of Francois Rabelais and popular culture of the Middle Ages and the Renaissance. M.: Literature, 1990 [in Russian].

2. Kovalskaya, I. (2016). Subjective-thematic basis and genre properties of musical comedy (on the example of the repertoire of the Odessa Academic Theatre of Musical Comedy named after M. Vodyanoy). Candidate's thesis. Odessa, 2016 [in Russian]. 